\title{
Innovando en el siglo XV: una propuesta de innovación docente en el Análisis filológico del Cuatrocientos
}

\author{
Ana María Romera Manzanares \\ Departamento de Lengua española \\ Lingüística y Teoría de la Literatura \\ Universidad de Sevilla \\ anaromera@us.es \\ ORCID: https://orcid.org/0000-0001-6665-1023 \\ D.O.I.: $\mathrm{http://dx.doi.org/10.12795/JDU.2018.i01.95}$ \\ Pp.: 1692-1706
}

\section{Resumen}

En este trabajo presentamos los cambios y avances metodológicos en la planificación de la asignatura Análisis filológico de textos hispánicos con especial atención a las innovaciones introducidas en el tema que trata el cambio lingüístico del siglo XV. Nuestro objetivo principal es dotar al alumno de herramientas procedimentales que le permitieran elaborar hipótesis sobre la datación de un documento desconocido a través del estado de lengua que presenta. Nos centramos, por tanto, en establecer un modelo metodológico basado en problemas con el fin de reforzar y afianzar la confianza del alumnado a la hora de elaborar hipótesis sobre lingüística diacrónica. 
Palabras clave: Análisis filológico de textos hispánicos, Filología hispánica, innovación docente, docencia universitaria, experimentación docente universitaria.

\section{Breve descripción del contexto}

En este primer apartado pretendo exponer cómo he reformulado mi modelo metodológico en la asignatura de cuarto curso del Grado en Filología hispánica titulada Análisis filológico de textos hispánicos a través de las propuestas de Innovación docente trabajadas en el Curso general de docencia universitaria durante el primer cuatrimestre del curso 2018/2019. En esta ocasión he aplicado el cambio metodológico a un ciclo teórico concreto, Cambio lingüístico en el español del siglo XV, pero bien es cierto que, en los temas anteriores, Orígenes del español y el Castellano alfonsí, también he aplicado otras mejoras relacionadas con el nuevo modelo metodológico que perseguía implantar en mis clases y adquirir como propio.

En primer lugar, en este apartado introductorio describiré la asignatura y el grupo en el que he implantado el ciclo de mejora y qué otras actividades he propuesto antes de este ciclo y después de replantearme el modelo metodológico. El grupo de Análisis filológico del grupo correspondiente al curso 2018/2019 está compuesto por unos dieciocho alumnos que vienen regularmente a clase a pesar de que están matriculados veinticuatro, veintitrés de ellos son del Grado en Filología hispánica y solo uno del doble Grado en Filología clásica e hispánica. Se trata de una asignatura optativa de último curso, por lo que se supone en ellos un interés elevado y una formación teórica en Historia del español sólida, ya que la mayoría de ellos ha cursado las materias de Historia del español I, Historia del español II y Gramática histórica; algunos hay que todavía no han llegado a cursarlas todas, pero sí están matriculados en esta o en aquellas en el curso actual. Así pues, el primer día de clase ya me propuse cambiar, aunque 
fuera de forma gradual, el modelo metodológico y utilizar la teoría que traían de cursos anteriores y la voluntad que notaba en ellos, ya que habían elegido una asignatura optativa impartida a primera hora de la mañana, para darle la vuelta por completo al planteamiento de la asignatura.

El diseño de este ciclo de mejora docente parte de los contenidos teóricos elementales del tema que trata, como se adelantó, el Cambio lingüístico del siglo XV, si bien antes de explicar los detalles del ciclo de mejora, me gustaría detenerme en explicar brevemente en qué cambios metodológicos se enmarca el ciclo, ya que, creo, me sirve para contextualizar el diseño del mapa de contenidos del tema elegido.

Como introducción a la asignatura, en la primera práctica tratamos de organizar cronológicamente seis documentos de diferentes siglos por su apariencia y lengua. No sabían en qué siglo empezaba el orden, ni cuál era el más moderno, pero sí supieron desde el principio que no había dos para la misma franja temporal. Era un punto de partida general sobre el que construiríamos la primera hipótesis haciendo un examen de la materialidad del documento: la mise en page, esto es, la disposición, el material, el tipo paleográfico, etc. Me sorprendió gratamente que los alumnos dudaran poco en la mayoría de documentos y siglos. Una vez que comprobé mediante un cuestionario inicial que prácticas como estas tenían sentido y utilidad para ellos y, sobre todo, que su exposición a los documentos había sido escasa o nula, fui confeccionando el tema siguiente basándome en imágenes de documentos originales.

Así, seguidamente, comentamos en clase documentos de la Alta Edad Media extraídos del Corpus CHARTA y, después, textos como el Poema de Mio Cid, el Auto de los Reyes Magos o el Libro de Alexandre a través de la consulta de su reproducción facsimilar, accesible gracias a las digitalizaciones ofrecidas, entre otros, por la Biblioteca Nacional de España o el Portal de Archivos Españoles en lugar de hacerlo a través de ediciones o transcripciones. Esto 
supuso un cambio drástico en la organización de la asignatura y una modificación profunda de mis planteamientos metodológicos.

\section{Diseño previo del ciclo de mejora docente}

Como se expone en el gráfico que sigue, pensaba impartir la asignatura de manera que tuvieran una explicación teórica antes de ponernos a trabajar todos juntos en las características lingüísticas del texto, trabajo en el que yo los pensaba guiar exponiendo los datos principales en los que había que fijarse según diferentes épocas y textos: es decir, pretendía partir de la teoría para llegar a la práctica:

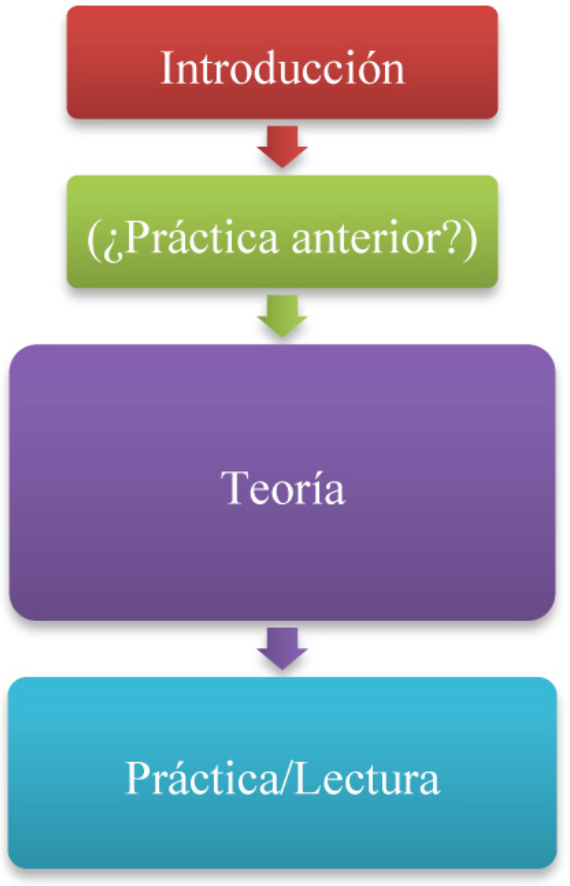

Figura 1. Modelo metodológico inicial

Ahora bien, este curso de innovación me hizo reflexionar sobre el procedimiento de este análisis y sobre la metodología que quería seguir en clase: pensé que, en origen, 
no fue antes la teoría sobre las características de la lengua en cierto siglo, etapa, autor o texto, sino que fue primero el texto y de él se partió hacia la teoría; tampoco en un examen dado, sea de esta asignatura, sea de oposiciones, ni siquiera en un trabajo de investigación de posgrado van a tener siempre la datación, la localización, el autor o el título del texto, sino que tendrán que hipotetizar sobre estos datos a través del contenido y del estado de lengua que el texto presente.

No tenía sentido que, llegados a este punto y después de que mis alumnos hubieran cursado ya materias como las anteriormente citadas, yo impartiera los ciclos de mejora o pretendiera innovar en la asignatura de Análisis filológico dando teoría y trabajando desde el manual: mi idea fue la de llegar a la teoría partiendo del propio texto. Siguiendo este planteamiento, inicié mi primera clase diciendo aquello de ¿qué fue antes, el huevo o la gallina? Pregunta un tanto absurda que nadie sabía ubicar en aquel contexto, pero que minutos después identificaron a la perfección. Captada ya toda su atención, acto seguido pregunté si fue antes la teoría lingüística de los origenes del español o la Nodizia de kesos, los artículos sobre la lengua del Poema de Mio Cid o el mismo Poema, los manuales sobre el léxico del siglo XV o los textos cuatrocentistas donde evidentemente aparece esa renovación léxica.

Este punto de partida puede parecer obvio, pero, en mi opinión y según mi propia experiencia como alumna y docente, suele verse en Filología tanto la teoría como la práctica partiendo del manual. Bien es cierto que en clase de Historia del español hay que sentar unas bases teóricas que no podemos construir o reelaborar con los alumnos, no es ese un objetivo admisible, pero esta asignatura de Análisis filológico, concebida fundamentalmente como asignatura práctica, era el mejor espacio para que los alumnos, ya en su último curso, puedan quitarse aquella constricción de ver en el texto lo que señala el manual que hay. No vamos a descubrir nada que no se haya dicho, claro, pero se trata de que planteemos una práctica real: ante cualquier texto debemos recordar la teoría a través del estado de lengua que el texto presenta, no a partir de 
una datación o autoría que podamos ubicar en la teoría de los manuales. Es decir, se pretende que se reconstruya en cierto sentido la teoría a través de lo que se refleja lingüísticamente en el documento, de lo que pueden ver materializado en el mismo texto: grafías, formas verbales, pronombres, adverbios, etc.

Uno de los objetivos principales para mí en esta asignatura era que el alumno tuviera la suficiente confianza en construir su análisis a partir de lo que tiene delante y puede ver: el texto. El comentario filológico partirá aquí siempre del texto hacia el manual, nunca irá en el sentido contrario. El trabajo a partir de problemas, en nuestro caso los problemas son los textos de las diferentes etapas de la Historia del español, creo que ha funcionado bien: quería, además, dotar al alumno de seguridad y confianza para examinar el texto desde lo físico y realizar desde ese punto el razonamiento y exposición de los contenidos teóricos.



Figura 2. Modelo metodológico del CMD

Poco a poco los problemas se han presentado en clase como de mayor complejidad, esto es, dotados de menos 
datos sobre su procedencia, género o datación, y, aun así, creo que los alumnos han respondido acertadamente ante estas dificultades: sus explicaciones y razonamientos también fueron paulatinamente creciendo y mejorando. Las actividades de contraste se han basado en lecturas de especialización filológica y en comparaciones con otros documentos que señalaban con énfasis alguno de los rasgos mal reconocidos u obviados. Finalmente, cuando hemos llegado a conseguir la datación de la lengua del testimonio he reforzado lo trabajado ya en clase con exposiciones teóricas que suponían el cierre del ciclo o práctica.

De esto se desprende que la densidad de la materia iba creciendo, así como también iba creciendo la cantidad de textos y estudios disponibles para nuestras prácticas de Análisis filológico. De ahí que la idealización del mapa de contenidos del ciclo de mejora haya sido representada en forma de espiral dorada, forma que va expandiendo paulatinamente su base y extensión: también la asignatura, avanzaba en el cronograma cuatrimestral teniendo más base teórica y, sobre todo, más experiencia práctica:

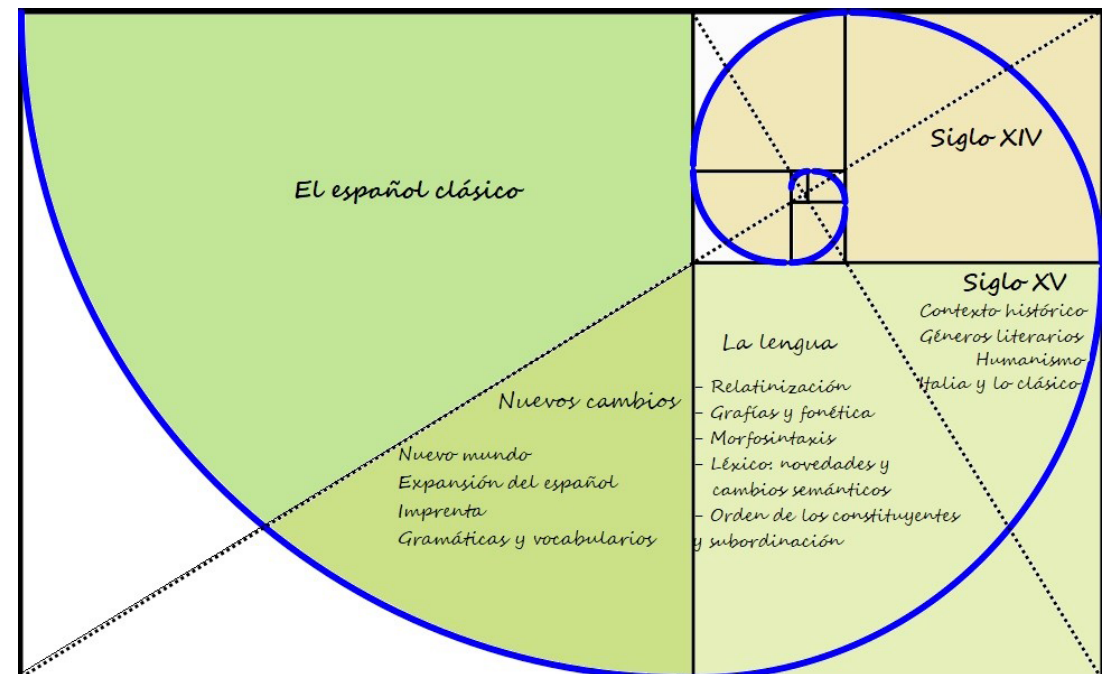

Figura 3. Mapa de contenidos del CMD

Jornadas de Formación e Innovación Docente del Profesorado | № 1 (2018) Reconocimiento-NoComercial-SinObraDerivada Internacional (CC BY-NC-ND 4.0.) 
Para ver las intuiciones de los alumnos sobre lo que se va a presentar en el nuevo ciclo, planteé un cuestionario con preguntas generales y asequibles según el ritmo que llevamos en clase. Después de ver textos correspondientes al periodo alfonsí y ya cerrado el tema correspondiente al siglo XIII les presenté el siguiente documento sin contexto, ni autor ni datación, ni introducción teórica:

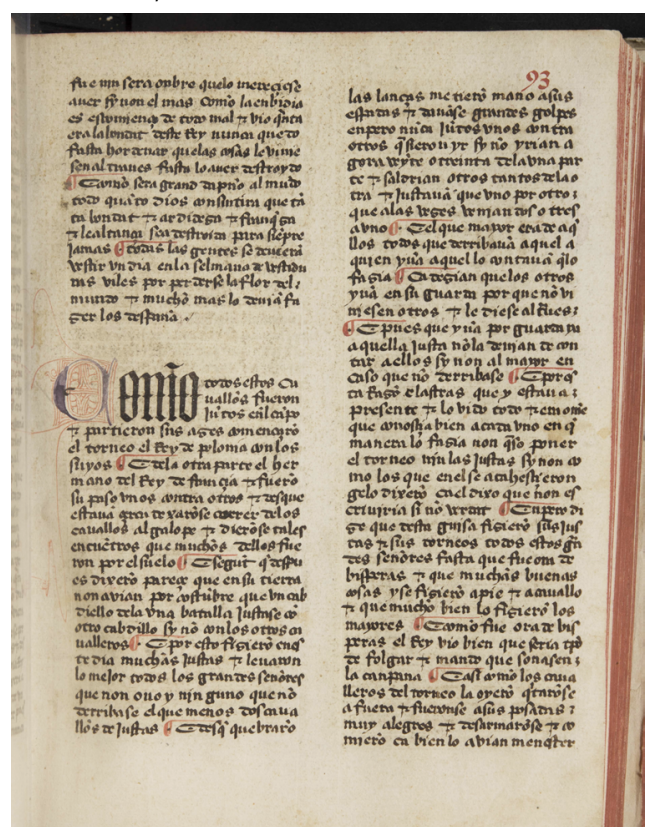

Figura 4. Primer documento cuatrocentista del CMD

El cuestionario serviría a la vez para ver cómo llevan la teoría de lo que llevamos visto, lo que recuerdan de la teoría del XV y, sobre todo, para ver si su intuición lingüística y su memoria les lleva a identificar esta nueva etapa de la Historia del español a través del estado de lengua que presenta este texto. Las preguntas propuestas fueron las siguientes:

1. En general, ¿te parece más o menos avanzado este texto con respecto a los ya vistos en clase?

2. ¿Te parece un texto con una construcción complicada? 
3. ¿Crees que tiene un estilo elevado? ¿Hay apego a lo culto?

4. ¿Este texto podría ser definido como conservador? ¿Preferirías su caracterización como innovador? ¿En qué?

5. ¿Crees que podríamos clasificarlo dentro de alguno de los géneros que hemos tratado?

6. ¿Te parece que presenta un sistema gráfico estable?

7. Las soluciones, por ejemplo, verbales ¿son siempre las mismas?

8. Piensa en cómo se enlazan las oraciones aquí: ¿hay algún cambio con respecto a lo que hemos visto?

9. ¿Dirías que en el léxico hay novedades?

10. Con todas tus respuestas sobre el estado de lengua de este texto ¿podrías indicar una fecha aproximada? ¿Qué es clave para ti? ¿Por qué no es anterior? ¿Por qué no posterior?

Con las respuestas, que para mí suponen la primera hipótesis (H1) que pretende dar respuesta a este nuevo problema, planteé actividades de contraste (AC1, AC2, etc.) que les hicieran reflexionar a ellos sobre si han ido bien encaminados o no en el cuestionario inicial. Estas reflexiones también las utilicé para ver dónde estaban los problemas a resolver y poder pensar así en cómo guiarlos para que los solventaran.

\section{Aplicación del ciclo de mejora docente}

El ciclo de mejora se empezó a aplicar el mes de noviembre, algo más tarde de lo que preveía, pero el tema anterior y el trabajo con los facsímiles nos entretuvo más de lo previsto. Aun así, nos lo tomamos como algo positivo en clase porque siempre todos tenían algo que aportar a la clase, todos los textos fueron comentados y todos los grupos compartieron su trabajo con los demás, por lo que he considerado esta tardanza como una muestra de la efectividad del cambio metodológico. 
Tabla 1

Organización del segundo ciclo de mejora

\begin{tabular}{|c|c|}
\hline Lunes & Miércoles \\
\hline 12 & 14 \\
\hline 19 & 21 \\
\hline 26 & \\
\hline
\end{tabular}

Las sesiones en la que se ha implantado el ciclo de mejora y las actividades realizadas durante estas clases se recogen en las siguientes tablas. He incluido el planteamiento inicial de la actividad y la realidad de las sesiones en una misma tabla para que sea más visible su comparación:

\section{Tabla 2}

Organización de la primera sesión del CMD

\begin{tabular}{|c|c|}
\hline \multicolumn{2}{|c|}{ Lunes 12 de noviembre ( $\left.80^{\prime}\right)$} \\
\hline Planteamiento & Realidad \\
\hline Actividad 1: 50' & \multirow{4}{*}{$\begin{array}{l}\text { Los tiempos variaron un poco, } \\
\text { pero, en general, todo fue en esta } \\
\text { primera sesión como pensé en la } \\
\text { planificación. }\end{array}$} \\
\hline $\begin{array}{l}\text { En primer lugar, para poner en situación } \\
\text { los conocimientos previos que se evalua- } \\
\text { rán en este segundo ciclo confecciono un } \\
\text { cuestionario dependiente de un texto } \\
\text { (PR) sin fecha, ni autor, ni contexto. Lo } \\
\text { que en clase llamamos 'crudo'. }\end{array}$ & \\
\hline Actividad 2: 30' & \\
\hline $\begin{array}{l}\text { Sobre ese cuestionario, algo escueto y } \\
\text { concreto hacemos entre todos unas bre- } \\
\text { ves matizaciones: utilizamos ejemplos } \\
\text { y empezamos a reflexionar sobre hacia } \\
\text { dónde vamos. Esta breve charla entre to- } \\
\text { dos nos permite identificar que lo que } \\
\text { estamos haciendo supone una hipótesis } \\
\text { (H1) sobre el texto dado. Hipótesis que } \\
\text { con las diferentes sesiones de este ciclo } \\
\text { podremos ir mejorando y actualizando. }\end{array}$ & \\
\hline
\end{tabular}

Jornadas de Formación e Innovación Docente del Profesorado | № 1 (2018) Esta obra se distribuye con la licencia Creative Commons Reconocimiento-NoComercial-SinObraDerivada Internacional (CC BY-NC-ND 4.0.) 
Tabla 3

Organización de la segunda sesión del CMD

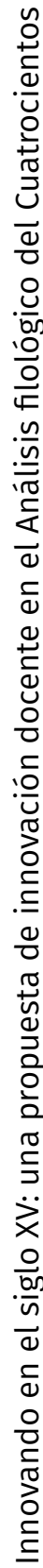

Miércoles, 14 de noviembre (80')

\begin{tabular}{|c|c|}
\hline Planteamiento & Realidad \\
\hline Actividad 1: 50' & \multirow[b]{2}{*}{$\begin{array}{l}\text { En este primer trabajo autónomo } \\
\text { me sorprendió verlos más perdidos } \\
\text { de lo que imaginé: los guío un poco } \\
\text { en la lectura y diferencias. Cogen el } \\
\text { ritmo y siguen solos. }\end{array}$} \\
\hline $\begin{array}{l}\text { Partiendo del documento anterior, } \\
\text { selecciono en la práctica de hoy el } \\
\text { mismo fragmento de texto, pero de } \\
\text { otro testimonio, es decir, utilizare- } \\
\text { mos una copia diferente del texto. } \\
\text { Los alumnos identifican claramente } \\
\text { estos conceptos y empiezan a en- } \\
\text { mendar su H1: empiezan a comparar } \\
\text { y modificar. }\end{array}$ & \\
\hline Actividad 2: 20' & \multirow[b]{2}{*}{$\begin{array}{l}\text { En esta segunda parte me dieron } \\
\text { dataciones algo dispares. Lo utilizo } \\
\text { para planificar la próxima sesión y } \\
\text { lo veo como un lugar común donde } \\
\text { trabajar con toda la clase. }\end{array}$} \\
\hline $\begin{array}{l}\text { En la breve puesta en común que si- } \\
\text { gue a esa práctica ellos mismos em- } \\
\text { piezan a notar las diferencias que } \\
\text { hay entre ambos textos y razonan } \\
\text { sobre qué piensan que deben modi- } \\
\text { ficar: el razonamiento sobre la teo- } \\
\text { ría de Historia de la lengua sale sola. }\end{array}$ & \\
\hline
\end{tabular}

Tabla 4

Organización de la tercera sesión del CMD

\begin{tabular}{|l|l|}
\hline \multicolumn{2}{|c|}{ Lunes, 19 de noviembre (80') } \\
\hline Planteamiento & Realidad \\
\hline
\end{tabular}

Jornadas de Formación e Innovación Docente del Profesorado I № 1 (2018) Esta obra se distribuye con la licencia Creative Commons Reconocimiento-NoComercial-SinObraDerivada Internacional (CC BY-NC-ND 4.0.) 
Actividad 1: 60'

Vamos hacia la construcción de la H3. En principio, partimos de que no coincidimos en la datación y caracterización del documento inicial, que es el que nos sirve para trabajar y en el que se basa la problemática de partida. Así las cosas, la H3 se construye ahora con las páginas finales del manuscrito inicial, es deEl planteamiento inicial se cumple en esta sesión, aunque intento responder a sus preguntas con otras preguntas: intento guiarlos en el razonamiento sin ofrecer la respuesta directamente. cir, comparamos aquí el inicio de un manuscrito dado (el texto de la primera sesión) con algunas de sus páginas finales (el texto de hoy).

Actividad 2: 20'

En la puesta en común podemos notar, en general, que el resultado de esta sesión es el adelanto de la daTambién tengo que tirar de ellos: parece que hay muchas hipótesis al tiempo.

tación inicial, por lo que consegui-

mos la mejora de la H1 en la H3.

Tabla 5

Organización de la cuarta sesión del CMD

\begin{tabular}{|c|c|}
\hline \multicolumn{2}{|c|}{ Miércoles, 21 de noviembre ( $\left(80^{\prime}\right)$} \\
\hline Planteamiento & Realidad \\
\hline Actividad 1: 30' & \\
\hline $\begin{array}{l}\text { En principio, planteo esta práctica como } \\
\text { cierre para que terminen de asegurar la } \\
\text { datación del documento. Para conse- } \\
\text { guir este objetivo, reparto otra copia del } \\
\text { mismo texto, pero esta vez de un ma- } \\
\text { nuscrito muy anterior al documento ini- } \\
\text { cial que es el que intentamos datar en } \\
\text { este ciclo. }\end{array}$ & $\begin{array}{l}\text { En principio y contra todo pronós- } \\
\text { tico piensan que ambos son de la } \\
\text { misma fecha a pesar de las dife- } \\
\text { rencias lingüisticamente gráficas } \\
\text { palpables }\end{array}$ \\
\hline
\end{tabular}

Jornadas de Formación e Innovación Docente del Profesorado | № 1 (2018) Esta obra se distribuye con la licencia Creative Commons Reconocimiento-NoComercial-SinObraDerivada Internacional (CC BY-NC-ND 4.0.) 
Actividad 2: 30

Para utilizar este documento más antiguo y construir una actividad de contraste, comparamos este último con un testimonio del siglo XIV: la intención es que se fijen en las similitudes gráficas y puedan determinar que nuestro docuLa práctica es útil, pero en lugar de adelantar el manuscrito inicial los lleva a pensar que es más antiguo, ya que comparte rasgos con estos antiguos.

mento inicial es algo posterior.

Actividad 3: 20'

Puesta en común: la comparación de los tres documentos debe ofrecer una visión clara y escalonada de la cronología de estos testimonios.

Tabla 6

Organización de la quinta sesión del CMD

\begin{tabular}{|c|c|}
\hline \multicolumn{2}{|c|}{ Lunes, 26 de noviembre ( $\left.80^{\prime}\right)$} \\
\hline Planteamiento & Realidad \\
\hline Actividad 1: 40' & \multirow[b]{2}{*}{$\begin{array}{l}\text { Intuyo algunas dudas y pienso que } \\
\text { quizá la falta de experiencia les haga } \\
\text { desconfiar de sí mismos. También } \\
\text { soy consciente ahora del alto grado } \\
\text { de dificultad de la actividad. }\end{array}$} \\
\hline $\begin{array}{l}\text { Con todos los textos sobre la mesa } \\
\text { y haciendo una comparación al } \\
\text { tiempo de todos ellos, así como un } \\
\text { breve análisis lingüístico, pretendo } \\
\text { que lleguen a datar correctamente el } \\
\text { texto inicial. }\end{array}$ & \\
\hline Actividad 2: 40' & \multirow[b]{2}{*}{$\begin{array}{l}\text { Esta última sesión y las dificultades } \\
\text { manifiestan que han tenido me de- } \\
\text { jan algo pensativa: ¿es un prejuicio } \\
\text { sobre la erudición italianizante del } \\
X V \text {, llevada y traída en la mayoría de } \\
\text { manuales? ¿Es falta de práctica? ¿ES } \\
\text { un mal planteamiento de las prácti- } \\
\text { cas del CMD? }\end{array}$} \\
\hline $\begin{array}{l}\text { Utilizando el cuestionario inicial, es- } \\
\text { pero ver cómo ha evolucionado su } \\
\text { reflexión sobre el texto inicial. Al fi- } \\
\text { nal les ofrezco la datación, el autor, } \\
\text { el título y el contexto y les doy breve- } \\
\text { mente la teoría lingüística que rodea } \\
\text { al texto y a los albores del siglo XV. }\end{array}$ & \\
\hline
\end{tabular}

En cuanto al análisis de la evolución de los alumnos, he de decir que la asistencia cayó a la mitad en la última 
sesión del ciclo debido al solapamiento con los exámenes de la convocatoria de diciembre, por lo que solo puedo examinar la evolución sobre siete cuestionarios. Por las limitaciones de espacio y por el interés que suscitan para este análisis las respuestas dadas a la pregunta 10, que, por otra parte, es la última y más compleja de todo el cuestionario, me centraré en examinar estas respuestas y de construir aquí las escaleras de aprendizaje.

Los resultados de estos siete alumnos en el primer cuestionario muestran los siguientes porcentajes:

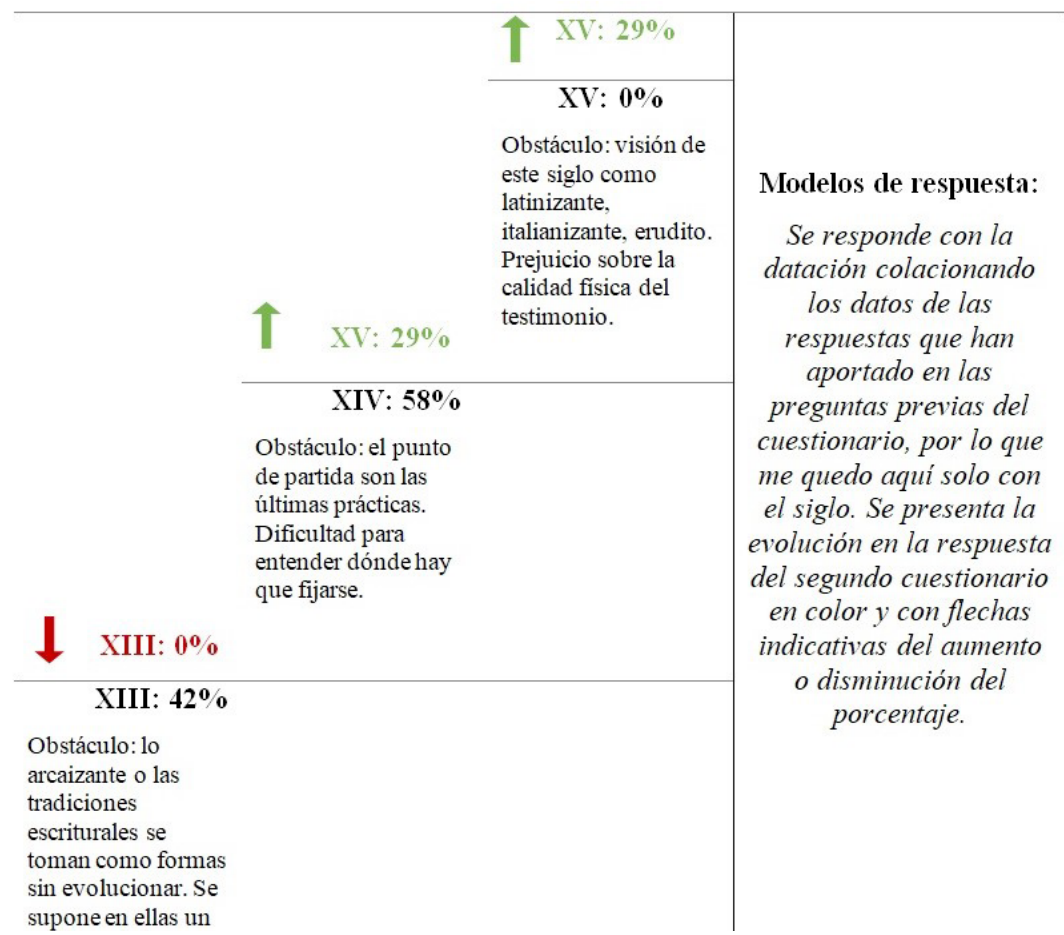

Figura 5. Escalera de aprendizaje

\section{Evaluación del ciclo de mejora docente}

Mi experiencia ha sido muy gratificante, estoy muy satisfecha con lo aprendido en el curso y feliz por haber confirmado cuánto podemos ofrecer y ganar en clase como profesores desde el punto de vista de la Innovación docente. 
Un breve análisis, después de haber aplicado el CMD, me demuestra a mí misma que no esperaba ganar tanto con tan pocos cambios. Es cierto que la mejora del modelo metodológico inicial me ha llevado a planificar de nuevo y desde cero la asignatura, pero el gran esfuerzo ha merecido mucho la pena. Creo que el gran cambio en mi forma de impartir clase ha sido, en esta asignatura, el hecho de partir del texto y creo que ha sido beneficioso para el alumnado: todos ellos, en una reflexión sobre el cambio metodológico, han dicho que agradecen poder trabajar de esta manera ya que no suele ser lo habitual y salen del aula de Filología sin haber hecho el verdadero trabajo del filólogo: partir del texto. El desarrollo de las hipótesis y la soltura que han adquirido a través de la práctica es palpable en cada una de sus reflexiones ante un testimonio nuevo, lo que parece mostrar que se ha logrado el objetivo principal de esta primera prueba de innovación.

\section{Referencias bibliográficas}

Bain, K. (2007). Lo que hacen los mejores profesores de universidad. Valencia: Universitat de Valencia.

Finkel, D. (2008). Dar clase con la boca cerrada. Valencia: Universitat de Valencia.

Porlán, R. (2017). Enseñanza universitaria. Cómo mejorarla. Madrid: Morata.

Jornadas de Formación e Innovación Docente del Profesorado I № 1 (2018) Esta obra se distribuye con la licencia Creative Commons 